\title{
Los orígenes de la "gran aventura»: De Gaulle antes del gaullismo (1914-1940)
}

\author{
Gaetano Quagliariello
}

Francia se prepara para celebrar el cuarenta aniversario de su quinta constitución republicana. $Y$ aunque no es competencia del historiador prever el futuro, no es fácil profetizar que la ocasión pondrá de manifiesto el final del "mal francés» y la estabilización de un nuevo modelo republicano. Como apoyo de tal afirmación no podemos referirnos sólo a sus próximos cuarenta años: la Tercera República duró un tiempo bastante más largo. Aún más relevantes del tiempo transcurrido, son las pruebas que la Constitución del 58 ha tenido que afrontar y ha sabido superar. Ha conseguido sobrevivir al propio fundador, ha consentido la alternancia de fuerzas distintas en el poder, ha afrontado y superado la dificil prueba de la convivencia incluso ha vertebrado, aunque con problemas, la desaparición del segundo «monarca republicano» (en orden de tiempo e importancia).

Sobre todo la Constitución del 58, de tendencia derechista, consiguió a lo largo del tiempo conquistar una legitimidad erga omnes, proponiéndose como ejemplo paradigmático de una conseguida transición ${ }^{1}$. $Y$ de tales éxitos la historia del siglo $x x$ no ofrece muchos otros casos. Las primeras síntesis históricas dedicadas al siglo xx —-más allá de las diferentes metodologías e ideologías - se fundan en la interpretación de una doble transición: el paso de regímenes liberal-democráticos a regímenes autoritarios (o totalitarios) y la sucesiva victoria de la democracia ${ }^{2}$. Al centrar dicho tema se ha dejado inevitable y justamente en un segundo plano otro tipo de tran-

\footnotetext{
1 Es ésta la tesis de fondo que sostiene el «clásico" de O. SuHAMEL, La gauche et la $V$ République, PUF. Paris, 1980, passim.

2 Es éste el motivo común de "storie coritrapposte" de F. FURET y E. J. HOBSBAwM, cfr. F. Furet, Le passé d'une illusion. Essai sur lidée communiste au xx siècle, Laffont-Calmant-Lévy, Paris, 1995; E. J. Hobsbawm, Age of Extremes. The Short Twentieth Century 1914-1991, Joseph London, 1994.
} 
sición que también merece atención: la sucesión de los diferentes modelos de democracia. El cambio de un ideal democrático dotado de una propia definición cultural y de específicas caracteristicas institucionales, a una concepción diferente del juego democrático, en algunos aspectos, incompatible con el precedente. El paso de la IV a la V República representa, de la forma mejor, dicho ejemplo de transición.

En las transiciones "de la democracia a la democracia", la relación entre ruptura y continuidad se presenta un poco matizada, respecto a los hechos sangrientos que han recorrido todo el siglo $\mathrm{XX}$. Y para comprender el juego de interacción entre los dos términos es indispensable que el análisis histórico sepa transmitir el estudio del "corto plazo» - de los hechos, de los acontecimientos - con la investigación destinada a perdurar. Si se remite tal precepto general al caso específico del paso de la IV a la V República en Francia, eso significa saber leer los hechos de mayo del 58 y los del cuadrienio sucesivo - que marcan una primera definición del nuevo modelo- en la más larga y vasta historia de la República en Francia. Por otro lado, si los estudios realizados presentan investigaciones importantes destinadas a "corto plazo» - al acontecimiento indicado como "La vuelta de De Gaulle al poder"- ${ }^{3}$, hay que constatar con satisfacción la presencia de contribuciones que han privilegiado una perspectiva más amplia, indicando un camino de investigación que se tiene que continuar ${ }^{4}$. El presente artículo tiene como objetivo el de aportar una pequeña contribución en tal dirección. Toma en consideración del desarrollo del análisis histórico-político de De Gaulle "antes del gaullismo": es decir, antes que la sucesión de los acontecimientos iniciara el largo camino que encontraría en mayo de 1958 un seguro y estable resultado.

3 Entre otros. sólo por citar los "clásicos". cfr. R. Remond, Le retour de De Gaulle, Ed. Complex, Bruxelles, 1987; A. Sigfried, De la IV Republique, Paris, 1958; J. Ferniot, De Gaulle et le 13 mai, Plon, Paris, 1965; A. Debatty, Le 13 mai et la presse, A. Collins, Paris, 1960; O. Rudelle, Mai 58, De Gaulle et la République, Plon, Paris, 1988; A. AzAR, Genese de la Constitution du 4 octobre 1958. Solution gaulliste à la crise du puvoir, LGDJ, Paris, 1961; J. M. Denouin, La genèse de la $V$ République, PUF, Paris, 1988.

4 Compárense, a propósito, los estudios «pioneros» de M. Willians and M. Harrison, De Gaull's Republic Longmans, London, 1960, con un planteamiento más militante, de L. HAMON, De Gaulle dans la République, PIon, Paris, 1958. Cfr. también, C. MorazE, Le Géneral De Gaulle et la République. Ou la République ne civilise plus, Flammarion, Paris, 1970; AA.VV. De Gaulle et son siècle. La République, la Documentation française-Plon, Paris, 1992. En una perspectiva más amplia, se comparan en cambio C. Nicolet, lidée rèpublicaine en France (1789-1924) Gallimard, Paris, 1982; M. Agulhon, La République, vol. I y II. Hachette, Paris, 1990; P. IsOart e C. Bidegaray (editado por), Des Républiques trançaises, Economica, Paris, 1988: S. Berstein-O. Rudelle, Le Modéle républicain, PUF. 
La investigación sobre este periodo de formación no agota el discurso histórico ni por lo que se refiere a la ideologia del gaullismo ni tan siquiera por la relación entre De Gaulle y la idea republicana. Por otra parte, sería un error metodológico y una grave falta de sensibilidad historiográfica infravalorar la importancia de esta relación. Es en los años que preceden a 1940 cuando De Gaulle, lejos de sus ocupaciones politicas directas, madura alguna idea-fuerza y alguna convicción metodológica que es necesario descubrir en sus orígenes, para poder comprender tanto al personaje de Gaulle, como el fenómeno histórico del cual él ha sido su máximo protagonista.

\section{DE GAULLE EN EL FRENTE}

Antes de continuar, es necesario establecer tres premisas de orden general, que se tienen que considerar básicas para todo análisis sobre «De Gaulle antes del gaullismo". En primer lugar, habrá que tener presente que en los años en cuestión, De Gaulle es sólo un militar, apasionado por su trabajo, sanamente ambicioso, con una rápida y brillante carrera. Su principal preocupación, por lo tanto, no es orden político; incluso, cuando en el curso de los años Treinta se reduce su distancia de la política -respecto a la cual hasta entonces había tenido una instintiva prevención- eso ocurre porque, como se verá, las preocupaciones de su mundo le imponen tal contacto.

La pasión militar en De Gaulle - un tipo de vocación originaria como bien ha notado su mejor biógrafo, Jean Lacouture ${ }^{5}$ - promovida y alimentada por una pasión nacional que hay que considerar parte de su bagaje genético. De Gaulle lo heredó de sus padres: el padre, soldado valiente en la guerra franco-prusiana, infunde en todos sus hijos la búsqueda de la victoria nacional como objetivo capaz de justificar y dar sentido a toda una existencia. Tal propensión ha sido reforzada por la educación materna, aún más intransingente en su devoción a la patria y reacia a aceptar la República como una realidad por la que sacrificar el sentimiento monárquico originario.

De estas dos premisas se deduce directamente la tercera, la más importante para el trabajo que nos ocupa: por lo que se refiere al período

5 Cfr. J. Lacouture, Charles De Gaulle, t. I, Le rebelle 1890-1944, Ed. du Seuil, Paris, 1984, págs. 9-33. 
que toma en consideración este articulo, la atención de De Gaulle está dominada por el tema de la guerra mundial. La suya es una preocupación constante, que comienza en visperas de la Gran Guerra y que no cesará ni en el tratado de paz que selló el final. La guerra no representa sólo el hilo conductor capaz de explicar la evolución de la reflexión de De Gaulle. El futuro Presidente la percibe y la teoriza como la vertiente entre dos tiempos diferentes de la historia de la humanidad... En 1932, en Le fil de l'epée, que recoge las reflexiones de una larga temporada, De Gaulle ${ }^{6}$ hace explícita referencia a tal separación de épocas.

Escribe, de hecho, a propósito del periodo pre-bélico: «los contemporáneos tienen que hacer un esfuerzo para imaginarse los años de otros tiempos". En su análisis, la estabilidad de una época que le parece distante se contrapone a la imprevisibilidad del tiempo sucesivo; la lentitud de los cambios que caracterizaron los tiempos pre-bélicos contrasta con el ritmo incesante de innovación con el que él y sus contemporáneos se tendrian que comparar.

La historiografía ha sufrido durante mucho tiempo el debate entre quienes sostenían la afirmación de razones estructurales en la deflagración del primer conflicto mundial y quienes, en cambio, privilegiaban el significado de los acontecimiento contingentes ${ }^{7}$. El análisis de la correspondencia de De Gaulle representa, en tal sentido, un indicio interesante a favor de la primera tesis. Testifica que, en especial, después del resultado del conflicto ruso-japones ${ }^{8}$ los que tienen buena capacidad de lectura de los acontecimientos de una época pueden predecir el acercamiento del conflicto. De Gaulle, el 23 de junio de 1908, escribe al padre: «(...) desde hace tres años hay algo que ha cambiado en Europa y constatándolo, pienso en los malestares que preceden las grandes guerras" ${ }^{9}$. La carta en cuestión no habla sólo de la perspicacia del joven De Gaulle. Resalta también cómo su propensión a privilegiar una lectura egocéntrica del conflicto debe considerarse como limitada. Ya desde entonces, para De Gaulle la gran guerra es ante todo y sobre todo la victoria del conflicto franco prusiano. Tal convicción - postergada por toda la duración del conflicto- lo llevaria a no

Cfr. C. De Gaulle, Le fil de l'épee, Berger-Levrault, Paris, 1944, págs. 53-54.

Para una sintetica y más completa reconstrucción de tal debate, cfr. B. Vigezzl, Le origini della prima guerra modiale come problema di breve e lungo periodo, in "Storia Contemporanea", a. XXVI, n. ${ }^{\circ} 2$ de abril de 1955, págs. 189-208.

8 Por la importancia del conflicto ruso-japonés, como fin de un orden mundial eurocéntrico, cfr. E. HALEVY, Une interpretation de la crise mondiale de 1914-1918, en L'ére des tyrannies, Paris, Gallimard, 1938, págs. 171-199.

- C. De Gaulle, Lettres, notes et carnets 1905-1918, Plon, Paris, 1980, págs. 35-37. 
dudar nunca de que en el frente franco-alemán se jugaba la partida decisiva para el resultado final de la guerra. Así como - al final de la contiendale induciria, por lo que se refiere a la reflexión histórica, a infravalorar el hecho de que la intervención americana prevaleció sobre las fuerzas de la alianza. Por otro lado, no es éste el único problema del joven De Gaulle. Las primeras cartas a su madre, desde el frente, demuestran una idea todavia inmadura de lo que está viviendo como protagonista, tanto bajo el perfil de la comprensión histórica como desde el punto de vista estratégico.

También para De Gaulle -así como para la mayor parte de sus contemporáneos- la gran guerra representa un salto hacia lo desconocido. En sus exordios, él considera que se debe resolver en pocas, pero grandes batallas.

La previsión de una larga y enervante guerra de trinchera se le escapa de las manos; asi como su concepción estratégica sólo ofensiva, pone de manifiesto una infravaloración del papel de la ametralladora y del fuego nutrido, como factores que producirían innovaciones profundas en el desarrollo de los conflictos armados.

Considerando tales tomas de posición no hay que olvidar que esas han sido asumidas dentro de una lucha abierta y que, después, De Gaulle tendría la lucidez de enmendar estas impresiones originarias. La misma precaución se tiene que usar al analizar las opiniones expresadas por él, en las mismas circunstancias, sobre el régimen político francés. De hecho, cuando llegan las primeras dificultades y, en especial, la derrota de las fuerzas de la Alianza en los Balcanes, hacen brotar la aversión de fondo que De Gaulle tiene contra la Tercera República. Siempre en las cartas a su madre, se habla de "cruel ineficacia del régimen" ${ }^{10}$. En especial, está remarcado el excesivo peso del Parlamento y la consiguiente sumisión al poder ejecutivo. La crítica de De Gaulle afecta sobre todo a los "parlamentarios» que están representados como una casta lejana de la opinión pública, distanciada de las pasiones y de los problemas del país " ${ }^{11}$. Se trata de vicios preexistentes al conflicto que la guerra inevitablemente exaspera, llevando a De Gaulle a formular dichos juicios.

El 23 de diciembre de 1915 escribió a su madre:

"El Parlamento se vuelve cada vez más odioso y estúpido. Los ministros tienen literalmente todo el día ocupado por las sesiones de la Cámara

10 Ibidem, pág. 232. Cfr. también en el mismo sentido, págs. 273-274

11 Ibidem, pàgs. 243-244. 
y del Senado o de sus comisiones; por lo que se refiere a la preparación de las réplicas que tienen que dar; la lectura de las peticiones o de las órdenes estrambóticas del comerciante de vinos que la política lo ha transformado en diputado. Esos no podrian, aunque lo quisieran, encontrar tiempo de administrar su cartera o la autoridad necesaria para galvanizar a sus subordinados. Nosotros seremos victoriosos sólo cuando echemos a esta gentuza, y no habrá un francés que no grite de alegria, y en especial los soldados." 12

Aún más importante es poner de manifiesto cómo, en este momento, De Gaulle está convencido de que la ineficacia del régimen representa la verdadera ventaja que Francia concede al enemigo. No duda del resultado favorable del conflicto porque cree aún en la superioridad militar de su país, aunque un año de luchas ha deshecho la esperanza de una victoria inmediata. Pero está convencido de que en el campo de los regímenes políticos es el enemigo el que marca una indiscutible primacía, y justo esa superioridad le consentiria prolongar los tiempos de una lucha sin igual en el plano militar. El 31 de diciembre de 1915 escribe:

"sin duda el enemigo tendrá la posibilidad de prolongar aún la lucha, gracias, sobre todo a su energía y a su disciplina. Gracias sobre todo a la extrema e irremediable inferioridad de nuestro régimen republicano-parlamentario.» 13

La participación de De Gaulle en la primera guerra mundial el 2 de marzo de 1916 da un giro importante. Al noroeste de Douaumont, cae prisionero. Comienza así una nueva fase de su biografía, en la que la obsesión por la fuga para volver a la acción directa en primera línea, convive con una más distante y lúcida consideración de los acontecimientos que están trastornando al mundo. Forzado a estar lejos de los lugares donde se juega el destino de la patria, De Gaulle entiende la gran guerra comprendiendo ahora todas las novedades introducidas por tal acontecimiento en la historia de los conflictos armados. El análisis sintetiza todas las consideraciones históricas y estratégico-militares. Volviendo a leer el diario de los dias de prisión, no es difícil encontrar apuntes y consideraciones que convergerian sucesivamente en los principales ensayos escritos entre las dos guerras: "La discorde chez l'ennemi», "le fil de l'èpée" e "La France et son armé».

12 Ibidem, págs. 273-274.

13 Ibidem, pàgs, 280-281. 
Tal madurez de pensamiento se observa también en las notas del análisis que De Gaulle destina a los regímenes politicos. Ya en esta fase, la duda de que un sistema autoritario menos complejo y más disciplinario que un régimen representativo, pudiera acarrear ventajas en la dirección de la guerra - duda que se insinuó en las primeras cartas desde el frente enviadas a su madre- es definitivamente arrinconado. Justo en esa fase, de hecho, formula uno de los puntos básicos de su concepción del evento bélico, que después tendría modo de profundizar y de especificar: en la guerra la división de las tareas entre el poder militar y el poder civil constituye una "ley férrea" e inmodificable. De Gaulle, trazando las esferas de acción propias de los dos poderes, no tiene dudas en asignar al ejecutivo la dirección superior del conflicto ${ }^{14}$. Tal solución brota en linea directa de la consideración de las novedades aportadas a la concepción de la guerra desde el primer conflicto mundial. Esto ha debilitado la distancia entre la vida civil y el frente: la guerra de los ejércitos se transforma en la guerra de las naciones poniendo en juego, al lado de la fuerza militar, la coexión de los pueblos, el potencial económico, el funcionamiento de los regímenes políticos, la capacidad de las clases dirigentes.

Durante la prisión, la reflexión sobre los sistemas políticos no se limita a términos generales, sino que afecta plenamente el juicio sobre las instituciones francesas del tiempo. En tal sentido, dos lecturas tienen una especial importancia para De Gaulle: "La République des camerades" de Robert de Jouvanel y "Sophismes politiques de ce temps" de Charles Benoist. El primero de estos libros, publicado en 1914, pronto llegaría a ser un "clásico» de la crítica al parlamentarismo de la Tercera República. El ensayo consiente a De Gaulle corroborar sus objeciones al régimen: la mediación parlamentaria entre la opinión pública y el estado resultaría una mera ilusión, que cubre la unión de hecho entre los cuatro poderes (legislativo, ejecutivo, judicial y prensa), todos en las manos de una restringida oligarquía ${ }^{15}$. Pero ¿qué hay que sustituir del parlamentarismo puro de la "Repubblique des camerades?» Sería inútil buscar en las notas de De Gaulle una respuesta exhaustiva al problema. Sin embargo, algunos aspectos deben distinguirse. En primer lugar, la atención que él presta a la crítica que Charles Benoist dedica a la "pureza" de las formas de gobierno, acusada de representar un residuo de abstractismo iluminista que impediría la edificación de los siste-

\footnotetext{
14 En especial, la conferencia dirigida por De Gaulle a sus compañeros de prisión, entre finales de 1916 y principios de 1917 que aparece ibidem, págs. 460-497.

is Por el "clásico" del reformismo republicano, cfr. R. DE JOVENEL, La République des camarades, Grasset, Paris, 1914; para el comentario de DE GAULLE sobre el libro, ctr. id., Lettres notes. cit. pág. 389.
} 
mas politicos modelados sobre una realidad orgánica de la nación ${ }^{16}$. De Gaulle, compartiendo el punto de vista del hombre político de derechas, anota en su diario cómo sólo por la mezcla de diferentes modelos de gobierno pueden nacer sistemas políticos capaces de encarnar, al mismo tiempo, la unidad de la nación y su continuidad histórica ${ }^{17}$. Está ya aquí presente, en realidad, una implicita denuncia contra el sistema de exclusión al que ha llegado la Tercera República, cuya importancia puede ser todavía más apreciada a la luz de un pasaje de la conferencia que entre finales de 1916 y principios de 1917 De Gaulle dirigió a los compañeros de prisión. Se puede aquí percibir una neta y definitiva contraposición entre el modelo originario de la Tercera República — plasmado por las leyes constitucionales de 1875 y creado del pacto entre monárquicos y republicanos- y su sucesiva evolución histórica en sentido marcadamente parlamentario. De Gaulle, en especial, toma en consideración el originario papel institucional y la capacidad política de la presidencia de la República, para quejarse de cómo el significado de tal magistratura se ha desfigurado de la torsión parlamentaria que las vicisitudes políticas han asignado al régimen. Ya en esta fase, pues, De Gaulle teme que el Presidente de la República, excluido del poder ejecutivo y relegado a un papel de mera representación, ya no pueda volver a encarnar en contingencias excepcionales la unidad de la nación, acorde en un esfuerzo común contra el enemigo externo.

\section{ENTRE GUERRA Y POSTGUERRA}

Las reflexiones iniciadas en la prisión no han caído en el vacío y se recuperan en los años entre los dos conflictos mundiales. Pero, para comprender cómo evoluciona en este periodo la relación entre De Gaulle y la Tercera República, ante todo hay que considerar su estado de ánimo, una vez que ha vuelto a la vida civil. Todavía antes de conocer el contenido del tratado de paz, De Gaulle no cree que la victoria se pueda considerar definitiva ${ }^{19}$. Estima

16 Para el "revisionismo" de BENOIST, me permito remitir al lector a mi obra La politica senza partiti. Ostrogorski e l'organizzazionewe della politica tra '800 e '900, Laterza, Roma-Bari, 1993, págs. 245-261.

17 Cfr. C. De Gaulle, Lettres notes, cit. pág. 394. Es interesante notar, a este propósito, también la interpretación original y claramente filtrada por la lectura de la teoría de BENOIST, que DE Gaulle da del sistema de gobierno roosveltiano; cfr. ibidem pág. 329

18 ivi, pág. 473.

19 Cfr. en especial, la carta a su padre del 12 de marzo de 1919 y a su madre del 25 de junio de 1919, remitidas ambas en C. DE GAULLE, Lettres notes et carnets (1919-juin 1940), Plon, Paris, 1980, respectivamente, en las págs. 21 y 32. 
la partida con Alemania todavía abierta, hasta el punto de preocuparse de que la disminución demográfica puede constituir una desventaja para Francia en la contienda. Su juicio no cambia, ni siquiera después de la conclusión de la conferencia de Versalles. Está convencido de que los alemanes, en cuanto puedan, desatenderán sus ocupaciones tratando de obtener, a través de las armas, una revisión de los tratados ${ }^{20}$. Para De Gaulle, pues, la victoria conseguida representa poco más que un armisticio provisional. La guerra europea se presenta ante sus ojos como una guerra interrumpida pero no concluida, mantenida en pie por el conflicto entre las naciones, y no por el enfrentamiento ideológico provocado por la revolución bolchevique. La estancia en Polonia - donde se dirige a la vuelta de prisión para instruir a los oficiales de ese país- le ofrece una ratificación en tal sentido. En ese momento, es testigo directo del conflicto entre Rusia y Polonia viendo imponerse el sentimiento nacional sobre toda solidaridad de tipo ideológico o social ${ }^{21}$.

De todo eso se deduce, como de cada discurso sobre De Gaulle entre las dos guerra - tanto desde el punto de vista de la evolución de su pensamiento como si se trata de comprender la acción y las opciones contingentes - que se deba tomar como punto de partida la propensión a considerar el conflicto europeo adormecido y destinado a volver a empezar la vía de las armas. Tal convicción termina por reflejarse también en los análisis que le dedica a la guerra terminada hace poco tiempo. En la reflexión de De Gaulle "la guerra que fue" y "la guerra que será" son dos términos siempre presentes, que animan un juego de espejos y continuas llamadas que tienen como finalidad última espolonear a Francia para que se presente puntual a la nueva cita con el enemigo. Tal recorrido analítico se sintetiza en 1924 con la publicación de La discorde chez l'ennemie, la primera obra del De Gaulle escritor. En ella se examinan las razones que conducirian al imperio "guglielmino" a la derrota en la guerra del 1914$1918^{22}$. Ya, en las primeras páginas del libro ofrece un cuadro exhaustivo del universo cultural de la formación de De Gaulle: su ideal es el de una sociedad orgánica, en la que las diferentes formaciones sociales prevalecen sobre el individuo e instauran un orden fundado en la solidaridad y la dependencia jerárquica. Es conocida la metáfora a la que De Gaulle asigna la tarea de describir tal proyecto de sociedad:

\footnotetext{
Ibidem cfr. también la carta a su madre del 30 de agosto de 1919, pág. 41.

Durante la estancia de DE Gaulle en Polonia, cfr. J. Lacouture, op. cit., págs. 99-126.

22 Cfr. C. De Gaulle, La Discorde chez l'ennemi, Berger-Levrault, Paris, 1924. Las citas que aqui aparecen han sido recogidas en la edición de bolsillo publicada en 1973 por la editorial Plon.
} 
«En el jardin a la francesa, ningún árbol tratará de sofocar a los otros con su sombra, los parterres se adaptarán a ser geométricamente definidos, las fuentes no tendrán la ambición de transformarse en cascadas, las estatuas no pretenderán para nada imponerse solitarias a la admiración. De esto deriva, a veces, una noble melancolía. Puede ser que provenga de la impresión de que cada elemento, aislado, podría brillar más. Pero esto perjudicaría al conjunto y el visitante se maravilla de la magnífica armonía." 23

Por otra parte, es importante subrayar la fuerte propensión antiindividualista de De Gaulle, que convive con una aversión a todo tipo de determinismo histórico y social y, lo que más cuenta, con una delicada consideración del papel que desempeña la personalidad individual en la historia, en especial en los momentos en que está en juego el bien supremo de la patrir ${ }^{24}$. Justo tal conocimiento empuja a De Gaulle a concluir no sólo que los regímenes democrático-representativos son más eficaces que los autoritarios, sino también que los primeros son más idéneos que los segundos para asegurar la coordinación necesaria entre fuertes personalidades unificadoras y los diferentes poderes político-sociales de un país. El caso de la derrota de la Alemania "guillermina" se eleva, en tal sentido, a ejemplo paradigmático: sólo, desde un punto de vista superficial, el régimen autoritario puede parecer más eficaz y eficiente. En realidad, la historia de la primera guerra mundial demuestra su incapacidad para regular la relación entre el poder político y el militar y sobre todo, la ineptitud para dar vida a los liderazgos nacionales unificadores. Durante el conflicto en Alemania -es ésta la conclusión implícita en el discurso de De Gaulle- los partidos encuentran aún más espacio del que obtuvieron mediante un sistema enfermo por exceso de parlamentarismo ${ }^{25}$.

Dichas convicciones representan la conclusión de una nueva revisión de la guerra mundial iniciada por De Gaulle ya al dia siguiente de su epílogo. Una primera etapa de tal reflexión puede entreverse en las conferencias pronunciadas en 1921 en la Escuela de Guerra de Sain-Cyr. En éllas, De Gaulle expresa con claridad el convecimiento de que el conflicto ha modificado la función de los gobiernos y coloca el cambio en 1915; en ese año se comprende que la guerra no la ganaría el ejército más fuerte, sino el pueblo más sólido. El papel de los gobiernos, hasta entonces con-

\footnotetext{
Ibidem, pág. 10.

24 Compárense, en especial, los capitulos dedicados a La désobeissance du général Von Kluck, págs. 13-26, en Les relations avec les alliés, págs. 63-104.

2s. Ibidem, págs. 107-181.
} 
siderado secundario, cada día que pasa se vuelve más importante, así como la necesidad de encontrar liderazgos fuertes y seguros que sepan expresar la unidad nacional con vistas al peligro externo ${ }^{26}$. Estas tesis llevan a De Gaulle -en una sucesiva conferencia pronunciada en 1925, después de la publicación de "La discorde chez l'ennemie"- a reanudar las críticas a los inconvenientes de un régimen exasperadamente parlamentario que, según el, de esta manera, resultaria difícil garantizar una línea de continuidad en la conducción de la guerra ${ }^{27}$. Pero, tales críticas conviven con la defensa del sistema representativo y con la explícita especificación de la importancia del control sobre la acción del ejecutivo: "No se puede admitir - afirma De Gaulle- que, un gobierno, no importa cual, sin control ni autorización, hipoteque todo su porvenir» ${ }^{28}$.

Las consideraciones sobre el liderazgo encuentran, en cambio, un desarrollo importante en otro libro, también deudor como el primero de las observaciones recogidas durante la prisión: “Le fil de l'épée». Se trata de una obra que más que la anterior adolece de la desilusión por el descrédito del ejército durante la post-guerra. De Gaulle es consciente de la crisis moral en la que cayó Francia, por el alto precio pagado en el primer conflicto mundial. La reacción pacifista y el deseo inconsciente de evitar, cueste lo que cueste, una nueva prueba de las armas, mina el orden militar en sus raíces y De Gaulle se propone, incluso a través de la publicación del nuevo volúmen, provocar una reacción de orgullo dentro de su mundo. Dicha determinación - que se divulga en un estilo de escritura conciso y enérgico-, ha empujado a algunos críticos a presagiar en el texto la claudicación de De Gaulle ante el espíritu del tiempo, y hasta la predisposición hacia soluciones plebiscitarias, incluso autoritarias. Dichas lecturas no tienen en cuenta que en 1932, cuando "Le fil de l'épée" se da al editor, De Gaulle sabía ya perfectamente, no sólo los inconvenientes de un régimen autoritario, sino también, lo que habia supuesto la experiencia del Segundo Imperio de Bonaparte, y que estos elementos le habian empujado a subrayar la importancia de los mecanismos plebiscitarios como factor de empobrecimiento de la energía de la nación ${ }^{29}$. Su convicción de la necesidad de encontrar una relación entre Estado y opinión pública, diferente de la que el parlamentarismo puro había sabido

Cfr. C. De Gaulle, Lettres notes et carnets (1919-juin 1940), cit., págs. 190-204.

lbidem, págs. 229-234 y en especial pág. 233.

Ibidem, pág. 233.

Cfr. En especial, la conferencia sobre Sedán, pronunciada en Saint-Cyr en 1921, que aparece en C. DE GAULLE, Lettres notes et carnets (1919-juin 1940), cit., págs. 170-190 y, en especial, pág. 173. 
asegurar, no provoca en él ninguna nostalgia por el ancien régime. De Gaulle tiene bien claro las características propias del régimen dictatorial, y estima que algunas peculiaridades de aquel periodo histórico son elementos estructurales independientes de la afirmación de los regímenes dictatoriales. Incluso llega a considerar que algunas de las características de esta época pueden ser aprovechadas por el ejército de un país dirigido por un régimen democrático-representativo, para resolver su crisis de prestigio ${ }^{30}$. En sus escritos, de todas formas, no se pueden encontrar debilidades hacia soluciones antidemocráticas, tanto menos en «Le fil de l'épée".

A esta conclusión se llega después de una consideración del libro sin perjuicios. Este, de hecho, contiene la definitiva afirmación de la teoría gaullista del predominio de las circunstancias sobre las ideologías no sólo en el ámbito militar, sino también en el de la acción política y hasta industrial ${ }^{31}$. Tal convicción, no sólo lleva a De Gaulle a oponerse a todo ideal de rígida planificación sino que lo empuja a enunciar una concepción de la acción humana bastante próxima a los cánones del individualismo metodológico. Lo que es más peculiar, es que estas tesis se deben investigar, superando el anti-individualismo de superficie, que a todos los efectos se puede considerar como un reflejo condicionado de su status de militar. En el capitulo dedicado a la acción de guerra, De Gaulle afirma explicitamente que los efectos de la acción humana en el devenir de los acontecimientos son incontrolables e irrevocables: «útil o no, oportuna o equivocada (la acción humana) tiene consecuencias indefinidas" 32 . Por eso, considera que cada decisión que se refiere a la forma de actuar puede mantenerse debido a la inteligencia y facilitarse mediante el instinto ya que, en definitiva, es principalmente de orden moral. Dichas consideraciones influyen directamente en la concepción del mando militar. Para De Gaulle, mandar no quiere decir supervisar el funcionamiento de un mecanismo abstracto. Al contrario, pretende tratar con hombres de carne y hueso, que a su vez manejan materiales. De estos hombres «algunos son buenos, otros menos; algunos lentos, otros rápidos, unos confiados y devotos, otros indisciplinados y celosos. Llevan dentro de sí, miles de razo-

\footnotetext{
30 Cfr. La carta a J. AuBERTin del 13 de noviembre de 1937 en la que plantea el problema de dar expresividad democrática a aquel ideal de organicismo social a través de los tiempos, al que el hitlerismo y el fascismo habian dado una respuesta autoritaria, en Lettres..., pág. 457. Cfr. también el articulo Métier militaire escrito por DE GaULle en 1934 para la revista de los jesuitas «Etudes", cit. en J. Lacouture, op. cit., pág. 218.

3! C. De Gaulle, Le fil de l'épée. op. cit., págs. 95-96 e 100.

32 Ibidem, pág. 28.
} 
nes para ser diferentes" ${ }^{33}$. Por eso, no es suficiente que el jefe sepa qué se tiene que hacer. Es todavía más importante, que tenga autoridad. Esta, a su vez, no puede considerarse un atributo abstracto: debe impregnarse de un estilo, de un carácter especial, de una personalidad ${ }^{34}$.

Llegados a este momento, es necesario una puntualización. Como ya se ha afirmado, el análisis de De Gaulle se dirige en especial hacia el mundo de las armas; pero eso no significa que las consideraciones sobre lo que, con lenguaje sociológico, se podría definir el "poder carismático", se limiten al ámbito militar. No sólo porque, siguiendo a Von Klausvitz, afirma explícitamente que la guerra no es nada más que la prolongación de la politica con otros medios ${ }^{35}$. Sobre todo porque De Gaulle aclara que determinados requisitos tienen que pertenecer no sólo al jefe militar sino a todos los conductores de hombres, ya sean soldados, profetas o políticos ${ }^{36}$. Los requisitos indispensables para la personalidad carismática son dos en especial: el carácter y el prestigio. Por lo que concierne al primer atributo, De Gaulle se refiere a la capacidad del hombre de acción de no dejarse hundir a la vista del evento. El carácter, en tal sentido corresponde al talento del artista: así como el talento marca la obra de arte con un sello especial de comprensión y de expresión, asi el carácter imprime su dinamismo de acción» ${ }^{37}$. Si el carácter -como el talento- puede perfeccionarse con la práctica y el trabajo, lo que De Gaulle define como "prestigio" es un don innato que evita todo tipo de análisis racional y no tiene nada que ver con el valor:

"Se ven personas notables por su inteligencia y virtud y que no tienen para nada la influencia que otros tienen, aunque éstos adolezcan de espíritu $y$ de corazón. ${ }^{38}$

El análisis sobre la "guerra que fue», junto con la evolución del cuadro internacional, provocó en De Gaulle la reflexión sobre la necesidad de liderazgos fuertes que actúen en regímenes democráticos y que sean capaces de presentarse puntuales a la cita con la "guerra que será». Como ya se ha dicho, desde la inmediata post-guerra, De Gaulle considera inevitable un nuevo conflicto europeo pero su análisis sobre este evento probable no se modifica. Evoluciona a la vista de la subida al poder de Hitler

\footnotetext{
Ibidem, pàg. 33.

Ibidem, págs. 32-34.

Ibidem, pág. 134. Hay que subrayar, que De Gaulle atribuye la imagen a Louvois.

Ibidem, pág. 76.

Ibidem, págs. 46-47.

Ibidem, pág. 67 .
} 
en Alemania, pero sin traicionar sus ideales. El centro de la atención de De Gaulle continúa siendo la conflictividad entre las naciones aunque en los últimos tiempos, los conflictos se centran en la prioridad de la lucha contra el totalitarismo. Es emblemática, la postura que De Gaulle asume con vistas al pacto de recíproca asistencia firmado por Francia y Rusia el 2 de mayo de 1935. De Gaulle reflexiona sobre lo acaecido en diciembre del año sucesivo - después de que el rearme de Renania por Hitler haya confirmado de forma elocuente sus temores-, en una carta dirigida a su madre. En su misiva confirma cómo la prioridad es la del punto de vista nacional y tal perspectiva coloca en el centro, la lucha contra Alemania. La llegada de Hitler y sus sucesivas iniciativas han exasperado tal conflicto latente, haciendo más urgente que Francia se prepare para el conflicto armado. De Gaulle ha leído el Mein Kampf y da al texto el valor de un verdadero y propio programa de acción; en dicho texto destaca como objetivo prioritario de Hitler, el de aniquilar a Francia, después de aislarla. Está convencido de que Francia, para defenderse, no podría contar ni con Italia - dispuesta a darle la puntilla, cuando el conflicto se orientara a favor de Alemania - ni con Polonia, por su debilidad y su facilidad para practicar el doble juego. También está convencido de que Inglaterra podría ofrecer una ayuda útil sólo a través de su flota, en cuanto está muy atrasada en el campo de las tropas de tierra y de aviación ${ }^{39}$. De ese cuadro, llega a una conclusión realista que confirma de nuevo la prioridad dada al elemento nacional sobre el ideológico: "No podemos rechazar la ayuda de los rusos, aunque no nos guste su régimen» ${ }^{40}$.

Nada mejor que tal afirmación nos representa a De Gaulle como un nacionalista consecuente. Él tiene siempre firme su punto de vista nacional pero lo sabe encajar en el cuadro mutable de los equilibrios internacionales. Sus reacciones ante los eventos decisivos de la segunda mitad de los años treinta (véanse, en especial, las cartas enviadas a su mujer sobre las conclusiones de la conferencia de Munich) ${ }^{41}$ demuestran la capacidad de percibir el interés nacional en el mutable cuadro de los equilibrios mundiales. Es, justo, esta capacidad la que le preserva de todo tipo de tenta-

39 También en este caso, De Gaulle demuestra una cierta aproximación y desinformación por lo que se refiere a la realidad de la aviación: infravalora lo que era el potencial inglés en el sector. Por otra parte, hay que poner de manifiesto que también en los proféticos análisis sobre cómo los tanques cambiarian el arte de la guerra, subestima los efectos del uso coordinado por los mis mos tanques con la aviación

41) Carta de Charles De Gaulle a su madre del 20 de diciembre de 1936, remitida en C. DE Gaulle, Lettres notes et carnets (1919-juin 1940) cit., págs. 441-443.

${ }^{41}$ Las cartas se remontan a septiembre-octubre de 1938; cfr, ibidem, págs, 473-477. 
ción. A diferencia de tantos otros nacionalistas no le habría tentado, ni siquiera por un momento la opción pacifista. En el momento decisivo, su pasión nacional sabe encontrar caminos diferentes, respecto a los demás, que también han bebido de las mismas fuentes.

\section{De Gaulle y la Tercera República: una relación en vías de evolución}

Desde una perspectiva analítica unitaria, la reflexión sobre la "guerra que fue" y sobre "la guerra que será» influye también sobre la relación entre De Gaulle y el régimen político francés a él contemporáneo. Según lo dicho anteriormente, existe una originaria desconfianza de De Gaulle, que en los primeros tiempos del conflicto mundial se convierte en desasosiego, sobre la forma de gobierno de la Tercera República. De forma más distanciada, algunos juicios expresados en pleno fervor de la postguerra, se revisan parcialmente. Por supuesto, en 1919 De Gaulle está aún convencido de que Francia se está ahogando en un océano de estupideces, vaguedades e insolencias administrativas, y desea por eso la llegada de un nuevo Richelieu o de un Lovois ${ }^{42}$. Tal deseo no le impedirá establecer una comparación a distancia con George Clemenceau -el hombre que en los años finales de la guerra y en la inmediata post-guerra ha personificado la República - que pone de manifiesto más equilibrio, si no equidad. A De Gaulle no le gusta Clemenceau y no tiene confianza en su forma de actuar ${ }^{43}$. El viejo «tigre» encarna a sus ojos los aspectos más detestables del "modelo republicano» de edad madura, que llegaría a modificar las características originarias del régimen: la hegemonía radical, el anticlericalismo. La exclusión de la Francia católica y conservadora que no quiere perder del todo el hilo de la continuidad con el tiempo de la monarquía. Tal aversión se expresa en una latente desconfianza en las dotes de negociador de Clemenceau y explota, con tonos caricaturescos, en una carta a su madre, en enero de 1920, en la que De Gaulle comenta su fracasada subida al Eliseo. Él se muestra sorprendido pero no abatido por la elección de Paul Deshanel: éste, respecto al "Padre de la Victoria», tiene la ventaja de estar, al menos, regularmente casado y con prole ${ }^{44}$.

Sería un error limitar al análisis de la relación Gaulle-Clemenceau a una prueba evidente de aversión. No hay que subestimar, además, que un

42. Cfr. la carta a su padre del 29 de enero de 1919, ibidem, pág. 15.

43 Cfr. a propósito de la carta a su padre del 12 de marzo de 1919, que aparece ibidem, pág. 21.

44 Cfr. la carta a su madre del 27 de enero de 1920, que aparece ibidem, pág. 69. 
juicio tan duro está formulado en una carta a su madre que, con toda probabilidad se habria quedado complacida. Un apunte de su diario contemporáneo, sobre el libro que Lecomte dedica a Clemenceau, destaca una pista interesante. En estas tenues líneas, de hecho, De Gaulle toma las distancias del panegírico formulado por el autor, refugiándose en un lacónico "la historia será capaz de dar un juicio más justo y más neto" ${ }^{45}$. Pero no puede evitar admitir que la irresistible fuerza de Clemenceau en los años 1917-1919 haya sido la de encarnar a Francia por entero: la Tercera República, incluso con todos sus defectos, fue capaz de obtener un liderazgo nacional que otras naciones, y en primer lugar, Alemania, no lo consiguieron.

Mientras aumenta la distancia de la guerra, la reflexión de De Gaulle sobre la Tercera República es más prudente y su aversión originaria se transforma poco a poco en perplejidad. Tal recorrido está emblemáticamente atestiguado por el juicio que expresa sobre Raymond Poincaré, otro grande de ese régimen, algún año más tarde respecto a la nota dedicada a Clemenceau. La ocasión viene una vez más por un libro; se trata, en este caso de L'invasión, obra del mismo Poincaré dedicada al 1915, y quinto tomo de sus memorias ${ }^{46}$. En el comentario, el juicio sobre el libro y el que se refiere al sistema político del que Poincaré es uno de sus representantes más ilustres se sobreponen, terminando por adherir el uno al otro. De Gaulle, ante todo, remarca el individualismo de Poincaré y su propensión a hacer autónoma la acción personal del espíritu de la nación: «No llama la atención en el libro la percepción intuitiva de lo que era la Francia de 1914. (Poincaré) nos habla únicamente de ministros, diplomáticos, Senado, Cámara, cuando estas insignificantes entidades no eran más que configuraciones abstractas. Él ha creído en los telegramas, en los mensajes, en las proclamas (...) cuando no había más que una ley terrible de la esperanza que empujaba el mundo a la guerra (...) Por otra parte, no tenía - como él mismo lo admite-contacto alguno con el pueblo" ${ }^{47}$.

Demasiado fácil divisar en las críticas el personaje, la crítica al régimen: el individualismo es un rasgo típico de la llamada «república de los parlamentarios", en la que una restringida élite de ponentes, incapaces

Ibidem, pág. 77.

46. El libro forma parte de las memorias de POINCARE, Au service de la France, Neuf années de souvenirs, publicado por Plon. Antes del tomo dedicado a L'Invasión, habian aparecido Le lendemain d'Agadir, 1912; Le Blakan en feu, 1912; L'Europe sous les armes. 1913; L'Union sacrée. 1914.

4. C. De Gaulle, Lettres notes et carnets (1919-juin 1940), op. cit. págs. 285-286 
de interpretar y de dar expresión política al sentimiento nacional, gobernaría con un juego institucional completamente fundado en el Parlamento, hasta el punto de dar origen a un verdadero y propio régimen de asamblea. La identificación entre el hombre y el régimen - junto con la perplejidad de De Gaulle sobre ambos- se hace explícita en el epílogo:

"Poincaré sería un empleado de primer orden si algún francés importante lo hubiera puesto a trabajar (...) Pero, abandonado a su suerte, nos parece semi-grande, semi-honrado, semi-comprensivo. En poco tiempo, un hombre de Estado a medida de la República" ${ }^{48}$.

Por supuesto, no se trata de una rehabilitación de la República, pero, en cualquier caso, estamos lejos de la condena sin apelación formulada durante la guerra. El juicio en cuestión se remonta a 1925: en ese hay un elemento permanente que no sería desmentido por el sucesivo recorrido personal e intelectual de De Gaulle; confluyen también otras sensaciones que, en cambio, desaparecerán cuando entre en contacto directo con ese mundo político que en 1925 conoce sólo superficialmente.

De los juicios sobre Clemenceau y Poincaré se insinúa el desasosiego de De Gaulle por el tradicional personal político de la Tercera República: por hombres "de otro tiempo", como él los definiria. Insistía sobre tal aversión hasta el último día de vida de la Tercera República. Dicha aversión sobresale, por contraste, incluso en las palabras de esperanza con las que De Gaulle saluda en 1929 la llegada al poder de André Tardieu: el hombre nuevo que puede llevar consigo el aire nuevo que sopla sobre una República envejecida ${ }^{49}$. Sí, estas esperanzas - que desde su punto de vista, con el tiempo se demostrarían mal planteadas-, representan precisamente un indicio para comprender el recorrido del "revisionismo" de De Gaulle en relación a la Tercera República. En la Francia de los años Treinta lo que separa a los "pacifistas a priori» de los que no excluyen la eventualidad de una retorno a las armas es la distinción entre sostenedores y adversarios de la Tercera República, hasta llegar a la más tradicional distinción entre izquierda y derecha. Dicho proceso afecta no sólo al mundo político sino que se extiende también al mundo militar. De Gaulie, en un momento de su biografía, intenta buscar un contacto directo con ese mundo político que siempre ha evitado. El origen de

46. Ibidem. Epilogo.

49 Cfr. la carta a su padre del 2 de noviembre de 1929, remitida ivi, pág. 354. En el pensamiento y la obra de TARDIEU renovador republicano, cfr. F. Monnet, Refaire la Répubblique. André Tardieu, une dérive réactionnaire (1876-1945), Fayard, París, 1993. 
dicha búsqueda tiene lugar al día siguiente de la publicación de un nuevo libro: el tercero de De Gaulle, titulado "Vers l'armée de métier» y que se publicó en $1935^{50}$. También en este caso, el centro de su atención lo ocupa la guerra europea. De Gaulle está convencido de que la política sólo defensiva emblematizada por la mítica "Línea Maginot", perseguida por mandos militares y acríticamente secundada por los diferentes gobiernos que se sucedieron en la guia de la nación, sea suficiente y peligrosa. Ésta no hubiera soportado el impacto del progreso tecnológico y en especial, del posible uso de tanques capaces de derrotar cualquier defensa. Considera, además, que Francia no tiene tiempo que perder. Tiene que poner en marcha cuanto antes un programa de construcción de tanques y dar vida a cuerpos especiales, aunque estos fueran extraños al ideal del ejército del pueblo de la tradición francesa desde los tiempos de la Revolución. Para De Gaulle la modernidad (insiste varias veces sobre esto en sus escritos y en la correspondencia) ${ }^{51}$ es exigir tal "revolución»: si el primer conflicto mundial ha comportado el paso de la guerra de los ejércitos a la guerra de masas, la guerra que se vislumbra al horizonte marcaría un nuevo salto cualitativo. Se llegaria a la guerra total en la que la innovación tecnológica jugaría un papel determinante (no causalmente, De Gaulle llama también al nuevo conflicto "guerra mecánica"), ${ }^{52}$ mientras las masas tendrian que garantizar ante todo el trabajo ${ }^{53}$.

De Gaulle considera su batalla decisiva para el futuro de la nación, pero la suya es una voz poco menos que aislada en el ambiente militar: el ámbito donde, hasta ahora, ha consumido todas sus energías y ambiciones. Es el efecto de dos circunstancias - la importancia de la puesta en juego y la incomprensión de su mundo- lo que le empuja a buscar una ubicación en la política. En este momento, nace también su relación con Paul Reynaud, el hombre de derecha moderada sobre el que De Gaulle tiene puestas todas sus esperanzas de victoria en un desafío en el que ve en peligro el futuro mismo de

5u Cfr. C. De Gaulle, Vers l'armée de métier, Berger-Levrault, Paris, 1934.

51 Cfr., en especial, la carta de DE Gaulle a P. Reynauo del 27 de febrero de 1938, que aparece en C. De Gaulle, Lettres notes et carnets (1919-juin 1940), op. cit. pág. 451.

5.2 Cir. la carta de C. De Gaulle a J.F. Perrette del 14 de enero de 1940, pág. 489, que aparece ibidem, pág. 489.

53 Este análisis está explicado con gran claridad en la memoria titulada L'Avenèment de la force mécanique, producida por DE GAULLE en ochenta ejemplares a principios de 1940 entregada a personalidades del mundo civil y militar. Del texto poseemos una versión reducida que aparece en la obra de L. NARCHIN Charles De Gaule, général de France, Paris, 1944, págs. 98-105. 
Francia ${ }^{54}$. Pero, Raynaud no es el único hombre político con el que De Gaulle estableció una relación de estima y colaboración. Entra en contacto con Millerand sacando la impresión de haber encontrado a un hombre de Estado de gran clase ${ }^{55}$. Lo que es más relevante, es que extiende el ámbito de sus contactos a la izquierda, tendiendo relaciones con el diputado socialista Joseph Paul-Boncour ${ }^{56}$, con el democráta-cristiano y animador de la "Jeune Republique» Philippe Serre ${ }^{57}$ y con Marcel Déat, también él diputado de la SFIO, ministro de Aviación en 1936 del gobierno Serraut y destinado a convertirse en el «hombre de los alemanes" en los años de Vichy ${ }^{58}$. Dichos contactos no se limitan a testificar la naturaleza transversal de la campaña de De Gaulle. Representan también un indicio sobre el ideal de hombre de Estado que él busca. De Gaulle considera que para un estadista no son suficientes las dotes de carácter y de prestigio. Éste debe también saber afirmar el interés de la nación sobre los intereses particulares y debe saber dispensarla, asimismo, de esta tarea cuando el peligro externo acecha y la unidad nacional se convierte en una clase de cantiguo instinto de la tribu que cuando oye al enemigo cesa las disputas intestinas a propósito de carneros o de mujeres y, casi por encanto, se pone de acuerdo para predisponer hondas y espadas" ${ }^{59}$.

Para De Gaulle, afirmar la unidad de la nación significa también superar la lógica de la exclusión típica del modelo republicano de la Edad de Oro de la Tercera República. A tal propósito, las cartas enviadas por él a

54 Sobre el papel de ReYnaud en el epilogo de la Tercera República compárese, en especial, el testimonio de Michel. Debré en Trois républiques pour une France, Mémoires i. Combattre, Albin Michel, Paris, págs. 141-171.

55 Cfr. la carta de C. De Gaulle a J. Aubertin, citada en C. De Gaulle, Lettres notes et carnets (1919-juin 1940), cit., pág. 392.

5.6 Cfr. a propósito de la carta de De Gaulle a P. Reynaud del 20 de noviembre de 1936, en la que se discute la alianza de hecho con Paul Boncour. La carta aparece en Lettres..., págs. 438439.

67 Cfr. a propósito de las cartas de Gaulle a P. Reynaud del 30 de enero de 1937, en la que hace referencia a las excelentes posiciones de Serre, desde el punto de vista de la izquierda. La carta está citada en Lettres..., pág. 446.

58 Cfr. A propósito de la carta De Gaulle a J. Aubertin del 13 de noviembre de 1937, en la que afirma que Marcel Déat "es, sin duda un grato talento y un valor", en la biografia de Déat. Mémories politiques, introduction et notes de Laurent This, Paris, Denoël, 1989.

59 C. De Gaulle, carta a P. Reynaud del 25 de junio de 1936, en Lettres notes et carnets (1919-juin 1940) op. cit., pág. 405. Sobre el ideal del hombre de Estado de De Gaulle y sobre el momento del peligro como momento típico de su manifestación, cfr. también Le fil de l'epée, op. cit., págs. 51-52; Id., Pour une politique de défense nationale, in "Revue Blue", n. ${ }^{0} 3,1932$ y, al fin, su carta a P. Reynaud del 14 de mayo de 1937, en Letters notes et carnets (1919-juin 1940), cit., págs. 448. 
Paul Reynaud son explicitas: para alcanzar el objetivo supremo de unir a la nación, la República necesita hombres nuevos con una nueva mentalidad ${ }^{60}$. Sobre todo es necesaria una acción de reforma que, partiendo del ámbito militar, confiera en profundidad las estructuras materiales, el ámbito intelectual y el sentimiento moral ${ }^{61}$. De Gaulle, en resumidas cuentas, invoca una acción contemporánea de ruptura y de cohexión, considerando que sólo de ese ambigüedad, de ese estrecho paso, se puede llegar a reunificar la historia y la obligación de la nación francesa. Lo que es importante considerar es que para esta tarea suprema, sus esperanzas son de hecho confiadas a hombres de ese Parlamento tan detestado. Es allí, más que en el ejército donde encuentra voluntad y energías dispuestas a resistir al pesimismo y a no resignarse a la decadencia ${ }^{62}$. En tal sentido, la foto de grupo del último gobierno de la Tercera República, es algo más que un documento histórico: es una metáfora en la que la larga silueta de De Gaulle - nombrado por Reynaud sub-secretario de Estado de defensa nacional y de la guerra- se proyecta sobre todos los ministros ${ }^{63}$. El proseguir de la historia ha modificado la relación entre De Gaulle y la Tercera República. Poco tiempo después, ese régimen quedaría aplastado bajo el peso de la derrota y para De Gaulle empezaría la gran aventura: afirmar la legitimidad de la nación por encima y contra la legalidad formal. De Gaulle lleva consigo a Londres también una raiz de ese régimen tan detestado. Nada mejor que el acalorado comentario de Mario Apellius - periodista de primer plano en la Italia fascista-. Para dar el sentido a esta imprevista continuidad: «En el último momento, para salvarse del hundimiento total, Francia tuvo que sacar del pasado dos viejos hombres como el Mariscal Pétain y el general Weygand, y los que formaban parte del período espiritual de la "revancha» y poner alrededor de ellos a varios hombres políticos conocidos por ser contrarios al Régimen derrotado. El llamado "comité nacional francés" de Londres, basado en la oscura figura del hebreo Mandel, el cual esconde su vileza orgánica detrás del penacho del señor De Gaule, (sic), testifica la mediocridad de un Régimen que, después de haber arrasado la Patria, la pisotea todavía con sus botazas (...) El titiritero Mandel, que mueve al valien-

60 Cir. Las cartas de C. De Gaulle a P. Reynaud del 3 de agosto de 1936 y a J. AuberTin del 10 de abril de 1938, que aparece en Lettres..., respectivamente a las págs. 408-409 y 468.

-1 Cfr. La carta de De Gaulle a P. Reynaud del 27 de febrero de 1938, que aparece en Lettres..., págs. 466-467.

62 La carta que De Gaulle envia a P. Reynaud el 2 de abril de 1936, en la que le pide que testifique en las manifestaciones del pesimismo militar que provienen del ejército; la carta que aparece en Lettres..., p. 402.

t3 Sobre esta foto y su significado metafórico, cfr.: J. LACOUTURE, op. cit. pág. 324. 
te de Gaule (sic) fotografía al Régimen al que Francia debe su actual situación catastrófica» ${ }^{64}$. Una vez más, una fotografía es metáfora de continuidad. También de dichas metáforas y de esta continuidad se ha nutrido la larga aventura gaullista.

-4 M. ApElLIUS, La tragedia de La Francia. Dalla superbia di ieri agli armistizi di oggi [crónicas de guerra], Mondadori, Verna, 1940, págs. 362-363. 